\title{
INVESTIGATION OF THE HEAT HANDLING CAPABILITIES OF DIII-D NEUTRAL BEAMLINIE INTERNAL COMPONENTS
}

by

J.C. PHILLIPS, C.B. BAXI, and R. HONG

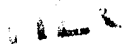

OCT ${ }^{1 h} \cdots$

$0 \leq+1$

OCTOBER 1993

\section{GENERAL ATOMICS}




\section{DISCLAIMER}

This report was prepared as an account of work sponsored by an agency of the United States Government. Neither the United States Government nor any agency thereof, nor any of their employees, makes any warranty, express or implied, or assumes any legal liability or responsibility for the accuracy, completeness, or usefulness of any information, apparatus, product, or process disclosed, or represents that its use would not infringe privately owned rights. Reference herein to any specific commercial product, process, or service by trade name, trademark, manufacturer, or otherwise, does not necessarily constitute or imply its endorsement, recommendation, or favoring by the United States Government or any agency thereof. The views and opinions of authors expressed herein do not necessarily state or reflect those of the United States Government or any agency thereof. 


\title{
INVESTIGATION OF THE HEAT HANDLING CAPABILITIES OF DIII-D NEUTRAL BEAMLINE INTERNAL COMPONENTS
}

by

J.C. PHILLIPS, C.B. BAXI, and R. HONG

This is a preprint of a paper to be presented at the 15th IEEE Symposium on Fusion Engineering, October 11-15, 1993, Cape Cod, Massachusetts, and to be printed in the Proceedings.

\author{
Work supported by \\ U.S. Department of Energy \\ Contract DE-AC03-89ER51114
}
GENERAL ATOMICS PROJECT 3466 OCTOBER 1993

\section{GENIERAL ATOMICS




\title{
INVESTIGATION OF THE HEAT HANDLING CAPABILITIES OF DIII-D NEUTRAL BEAMLINE INTERNAL COMPONENTS
}

\author{
J.C. Phillips, C.B. Baxi, and R. Hong \\ General Atomics \\ P.0. Box 85608, San Diego, California 92186-9784
}

\begin{abstract}
The current DIII-D neutral beam system is a nominal five second pulse length upgrade of a previous design rated for only $500 \mathrm{msec}$ operation. While the ion sources are rated for $60 \mathrm{sec}$ operation, in practice pulse lengths are limited both by the beamline internal components ability to handle the fraction of the power which is scraped off, and by the power supplies ability to provide pulse lengths of greater than $5 \mathrm{sec}$. This paper examines the capability of the existing DIII-D neutral beamline heat removing components both in terms of present and desired operating parameters. To date, at $2.5 \mathrm{MW}$ per ion source, pulses are limited to $3.5 \mathrm{sec}$ by beamline internal components, while at lower ratings of $2.0 \mathrm{MW}$ per ion source, up to $5 \mathrm{sec}$ pulses have been achieved. Recent advances and demonstration of the extraction of $3.5 \mathrm{MW}$ per DIII-D ion source give an even wider window of operating conditions. A full series of beamline thermocouple data has been collected to determine the heat loading and implied surface temperatures for the various DIII-D neutral beamline internal components. These data will be presented along with an analysis of the needs for specific component upgrades, given a desire for $10 \mathrm{sec}$ operation.
\end{abstract}

\section{INTRODUCTION}

In 1986, the DIII-D neutral beamlines were upgraded to accommodate the Common Long Pulse Ion Source designed by Lawrence Berkeley Laboratories, constructed by RCA under an industrial fabrication program with Princeton Plasma Physics Laboratory and General Atomics as the end users. The work to modify the beamlines to accommodate the resultant increase in nominal pulse length from 0.5 to $5 \mathrm{sec}$ was done at the same time the Doublet III tokamak was upgraded to the DIII-D design. The beamline design was constrained by the size of pre-existent and costly hardware such as the bending magnet yokes, and the beamline spools, thus compromises naturally had to be made between cost and performance. Compared to the original $500 \mathrm{msec}$ beam requirements the upgraded neutral beamlines have performed extremely well, capable of routinely and safely delivering $20 \mathrm{MW}$ from eight ion sources, at $3.5 \mathrm{sec}$ pulse lengths [1]. Longer pulse lengths, up to $5 \mathrm{sec}$, are achieved by de-rating the power delivered.

While the ion source would be capable of pulses up to $60 \mathrm{sec}$, power supply constraints limit operation to $5 \mathrm{sec}$. A program is underway to explore cost effec- tive extension of the operating parameter space of the entire neutral beam system, focusing both on the power supplies and beamline internal components. In addition to extending full power operation, knowing the exact boundaries of our operating parameters may allow us to run pulse lengths longer than $5 \mathrm{sec}$ at reduced power ratings without hardware modifications. This paper will present data that has been collected in support of this understanding and extension of the operating limits of the beamline's internal components.

\section{DIII-D NEUTRAL BEAMLINE INTERNAL COMPONENTS}

Each DIII-D neutral beamline has two ion sources installed and thus there are two beam paths through the system. Each neutral beam path contains a neutralizer cell, magnet for the $180^{\circ}$ bending of residual energetic ions, ion dump for the deposition of these ions, and a retractable calorimeter for measurement of either neutral or neutral plus charged particle beam [2]. In addition, the beam path is collimated by water cooled copper frames between the neutralizer and bending magnet, at the entrance to the bending magnet, at the neutral beam exit aperture of the bending magnet, the ion exit of the magnet, and finally at an absolute collimator before the duct entrance to DIII-D. All beam impinged surfaces, such as the pole faces of the bending magnet, are water-cooled copper. These components are illustrated schematically in Fig. 1. Of particular concern in this study were the magnet pole shields, magnet louvers, ion return collimator, and magnet exit collimator due to previous observations of slight surface melting of these components. In addition, melting has been observed in the "drift duct" aperture between the neutral beamlines and DIII-D. Unfortunately, this duct has no internal thermocouples.

\section{NEUTRAL BEAM THERMOCOUPLE DATA ACQUISITION}

The data used in this paper were collected during specific data collection runs with controlled neutral beam operating parameters, using a Nicolet digital acquisition and storage device. Time dependent temperature "waveform" data was thus acquired over a series of 60 shots for each component in question. The regular DIII-D neutral beam thermocouple acquisition system is used to take a reading from all beamline thermocouples just before a

Mamucript received October 12, 1993. This is a report of work sponsored by the U.S. Department of Energy under Contract No. DE-AC03-89ER51114. 


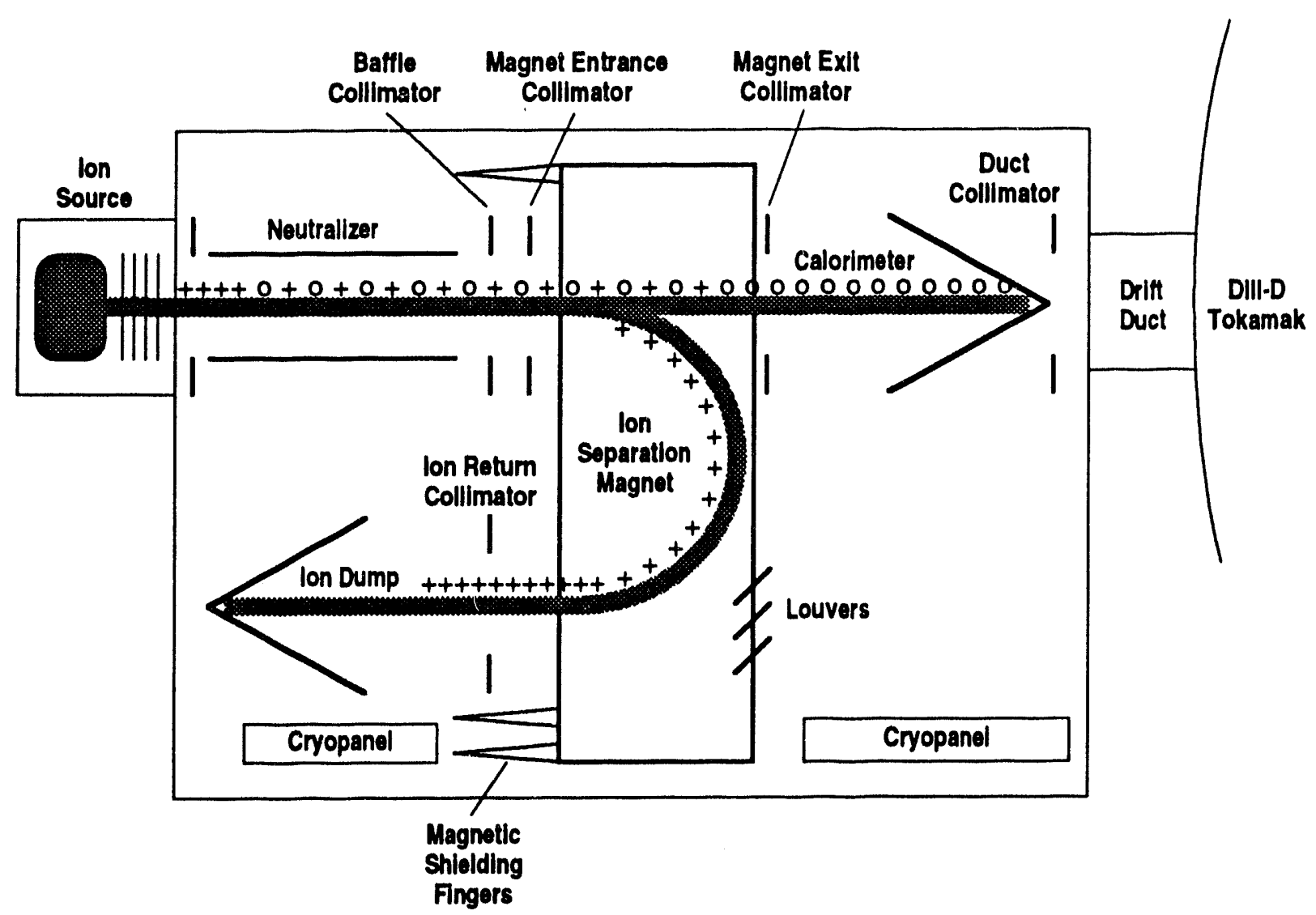

F1G. 1. A schematic view of DIII-D neutral beamline heat handling components.

shot is fired. At a predetermined time, typically $3.5 \mathrm{sec}$, after the shot is complete a second reading is taken and compared to the first. The operator is then provided with two numbers, the base temperature before the shot and the difference between the base and the final temperature after the shot, or " $\Delta T$." A programmed computer task runs after each shot and alerts the operator to $\Delta T$ 's which exceed alarm limits determined for each group or type of component. These $\Delta T$ 's have been used in the past to map the relative performance of various beamline operating conditions, but it has always been known that, depending on the component in question, the delay in accomplishing the second "read" of the thermocouples can result in missing the peak of the actual temperature rise.

\section{A NOVEL THERMOCOUPLE INSTALLATION SCHEME}

In 1989, the misapplication of current to one of the $330^{\circ}$ beamline bending magnets necessitated the replacement of several magnet louvers. Previous slight melting of louvers in other beamlines had also been observed, and the opportunity was used to redesign the louvers to provide a more substantial target. In addition, a new thermocouple installation technique was used which provides an excellent measure of the true surface temperature. A through hole is drilled in the copper component, the thermocouple junction is formed, inserted through the hole from the rear and the junction is "puddled" becoming part of the surface of the component. This technique has been used on thinner components such as louvers and the protective plates covering the top and bottom openings of the calorimeters, and was adopted in part because it does not require a furnace braze cycle for the thermocouple installation and facilitated in-house repairs performed inside the beamline. Readings taken from thermocouples using this installation technique provide an accurate measure of surface temperature with a fast response time. The disadvantage is that if the thermocouple is read several seconds after the shot, as is done with the regular DIII-D-NB acquisition system, a significantly lower temperature is observed due to the fast response and fast cooling of the surface location. An example of the thermocouple placements and resultant response is shown in Fig. 2, compared to that of a thermocouple measuring the bulk response of a magnet exit collimator. Bulk temperature rises of components such as the magnet exit collimator are a function of the power deposited on the component and thus measurements taken using the embedded style thermocouples scale linearly with the pulse length at a particular power level, whereas the temperature measurements recorded by thermocouples using this new installation technique show initial rises that are classical surface measurements and thus scale as the square root of the pulse length. In most cases damage observed in the neutral beamlines 


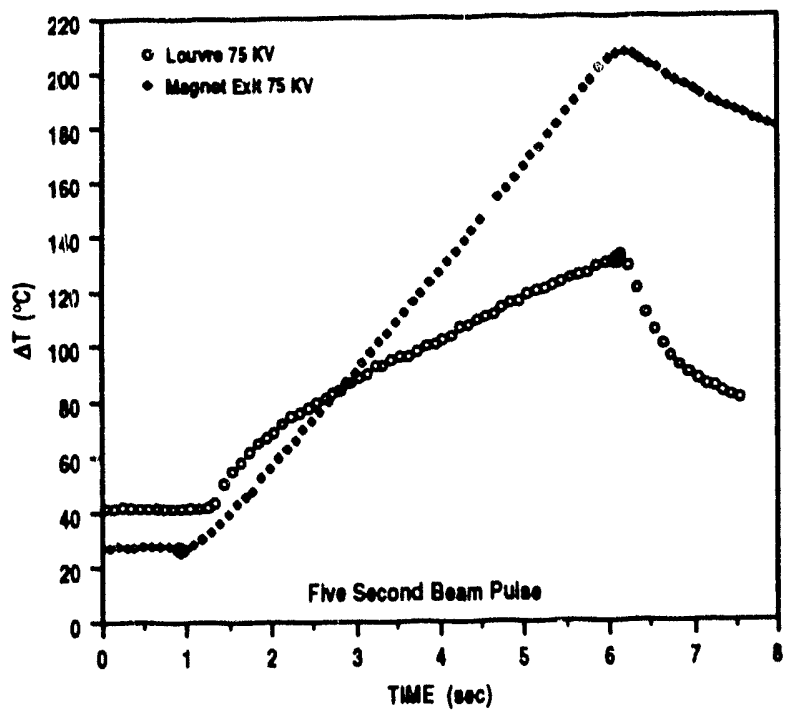

Fig. 2. The two thermocouple placements, one a surface mount, and the other a more traditional method which measures the bulk temperature, give different time-dependent responses, the surface mounted louver being a function of the square root of the pulse length due to conduction, the embedded magnet exit a linear function of the power deposited on the component.

involves localized surface melting, and thus it is really the measured or inferred surface temperature that is of interest. These new thermocouples provide this unequivocally when acquired as a time dependent waveform.

\section{MAPPING OF THE BEAMLINE OPERATING WINDOW}

A series of shots was taken on one beamline at beam energy of 55, 60, 65, 70, and $75 \mathrm{keV}$. Perveance was held constant at $3.0 \mu \mathrm{p}$, and at each beam energy level shots were fired at $0.5,1,2,3,4$, and $5 \mathrm{sec}$ pulse lengths, with temperature waveforms on key components recorded. For each power level, a fit was performed against the 0.5 through $5 \mathrm{sec}$ data, and an allowable pulse length extrapolated given an allowed temperature rise on the component. In this case, $200^{\circ} \mathrm{C}$ was used as the allowed limit. The data from all these shots were combined and plotted to provide an operating space map for critical beamline components, and is shown in Fig. 3.

This map provides operating parameter limits. In addition, the relative constraints provided by various beamline components can be observed and targeted for future engineering improvements.

This data has been used as a basis for exceeding the five second pulse length limit, with four ion sources injecting almost $2.0 \mathrm{MW}$ each for $6 \mathrm{sec}$ in support of DIII-D plasma physics experiments in September 1993.

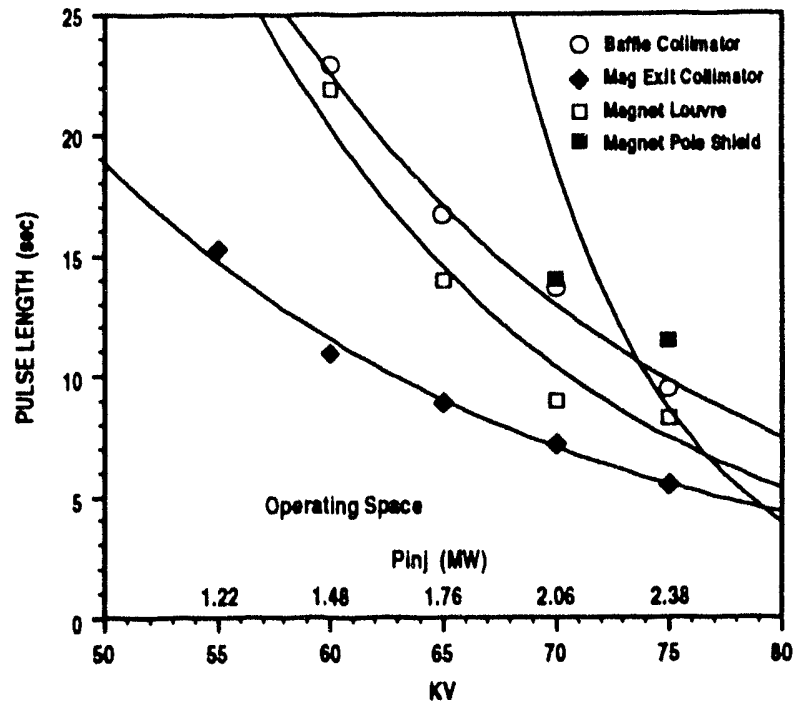

Fig. 3. The data is fitted and then plotted to produce a map of the allowable operating window for the neutral beamline somponents.

\section{IMPLICATIONS FOR \\ THE THERMOCOUPLE ACQUISITION SYSTEM}

Thermocouple data acquisition can be difficult in electrically noisy environments. Signals are at the millivolt level and by their very nature the thermocouples are spread out in areas close to the tokamak, a large inductive device, often with long paths to the data acquisition equipment. The original two point thermocouple read system was selected for two reasons. (1) The hardware is less expensive since no local camac memory is required. (Expense is a significant consideration when one considers that there are almost 1000 thermocouples in four beamlines.) (2) The second thermocouple reading can take place after electrical noise induced by the tokamak shot has dissipated. Unfortunately, this means that the peak temperature is often missed when the system is optimized for DIII-D injection. Two alternatives exist to improve this situation. (1) Using the observed temperature decay time constants gathered in this study, component specific tables can be derived which allow an estimate of the peak temperature. Temperature decay time constant tables would have to be customized not only on the basis of component type (due to varying thermocouple depths and component masses) (Fig. 4) but on the basis of the power level. This will become practical with the introduction of faster and more powerful DIII-D neutral beam computer systems to be implemented in the next year or two [1]. The advantage to this is that it does not involve new data acquisition hardware investment. (2) The acquisition system itself could be improved to provide noise-free time dependent data. This is likely to be an expensive venture with no guarantee of an absolute degree of success, in that certain portions of unshielded wiring within the beamlines are not practically replaceable. 


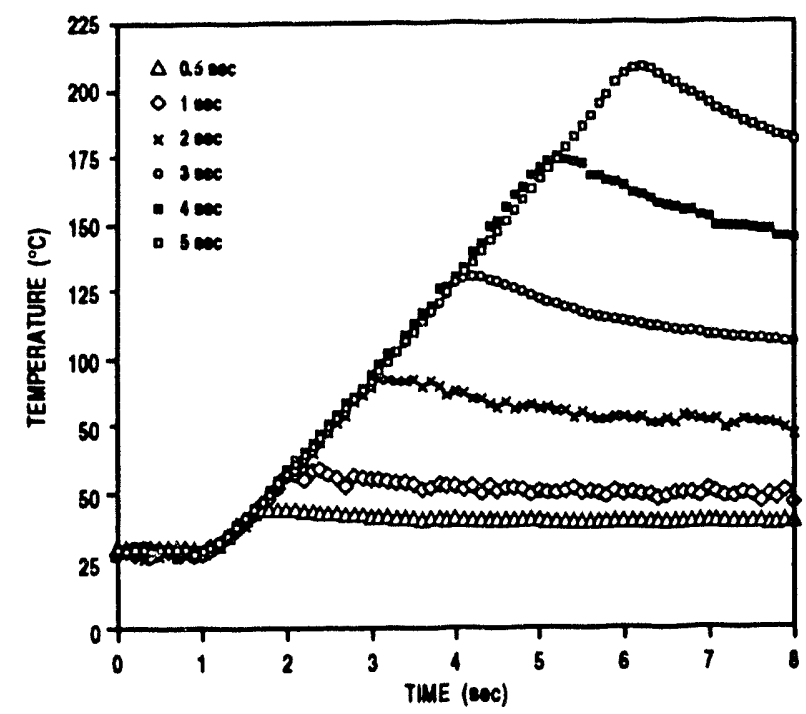

Fro. 4. Data from the magnet exit collimator for 0.5 through 5 sec pulses at $75 \mathrm{kV}$ is overlaid, showing both good repeatability and that a fitting algorithm will be dependent both on voltage and pulse length.

guarantee of an absolute degree of success, in that certain portions of unshielded wiring within the beamlines are not practically replaceable.

\section{THE NEUTRAL BEAM DRIFT DUCT}

Melting has been observed in the drift ducts during inspections and was thought to be an area of concern for extended pulse length operation. Re-ionization of energetic neutral particles occurs in the drift duct proportional to pressure. The trajectories of these charged particles are bent by the tokamak's magnetic fields, and they hit the walls causing a further rise in pressure leading to a runaway situation. Pressure rises and other edge effects are also caused by plasma disruptions and

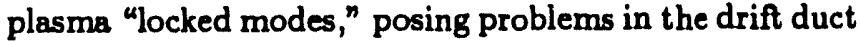
area [3]. There are no thermocouples installed in the DIII-D neutral beam drift ducts to aid in diagnosis of the problem, and it was once thought that only complicated magnetic field measurements and trajectory calculations could solve this problem. The development and installation of a logarithmic amplifier which processes the signal from a photo-diode sensitive to visible light in the drift duct has led to a viable solution. A real-time interlock now stops a beam pulse if the visible light in the drift duct rises to unacceptable levels. This level has been determined by successively reducing the trip point to the point where no new damage has been detected in the drift ducts in the last several inspections. Waveforms from this diagnostic (Fig. 5) indicate that when the ducts are clean and conditions normal, extended pulse lengths can easily be supported with the real-time interlock preventing damage in case of unacceptable or accidental conditions. This interlock has proven to be extremely reliable.

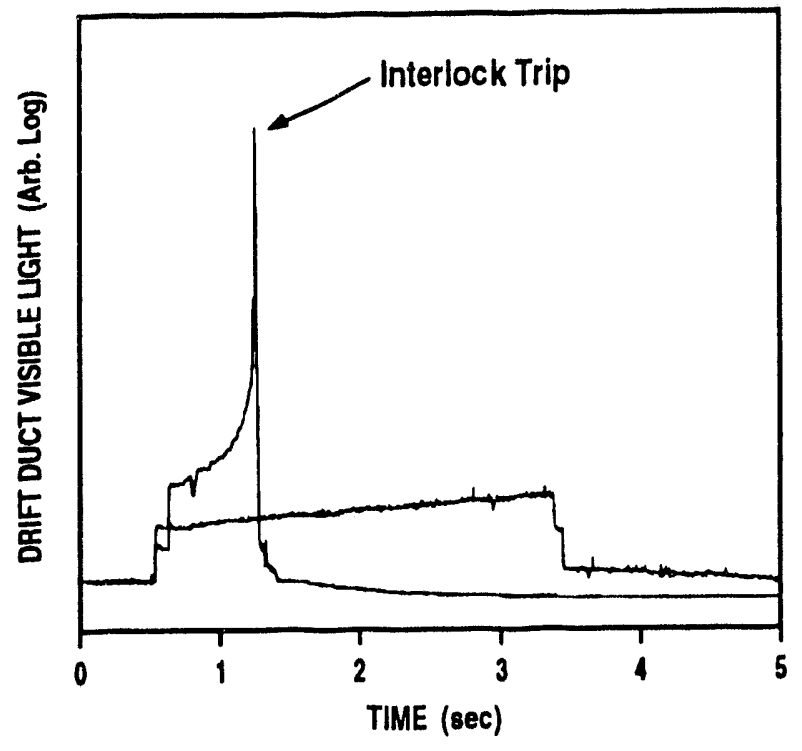

Fig. 5. A stable drift duct photo diode signal (dashed) is compared to that from unstable conditions (solid). A real-time interlock interrupts the beam in the case of damaging runaway conditions.

\section{OTHER IMPORTANT FACTORS}

Damage in the bending magnet area, particularly the pole face shields is of great concern since replacing these components would require removal of the beamline from the DIII-D machine hall and significant tear-down labor to remove the 7 ton magnet assembly from the beamline. For this study, data was taken under normal ion source and beamline operating conditions. Changes in these conditions can greatly affect the power loading seen by specific components. In particular, the power deposited on the bending magnet pole shields is very sensitive to the neutralization efficiency of energetic ions within the neutralizer cell. While this is typically $68 \%$ [4], occasionally failures have been observed of the gas puffing system to the neutralizer cell resulting in decreased neutralization efficiency and markedly greater power loading on the pole shields as seen in Fig. 6. Especially with longer pulse lengths, such failures can easily result in unacceptable operating conditions and resultant damage to beamline components. To address this problem, a real time interlock based on the presence of acceptisble flow of neutralizer gas during the beam pulse is being installed and tested, and will be essential to zare extended pulse operation.

The damage to the $330^{\circ}$ right ion source bending magnet mentioned previously resulted in the implementation of a real-time interlock for the appropriate magnet current versus ion source operating voltage, and no further such incidents have occurred. 


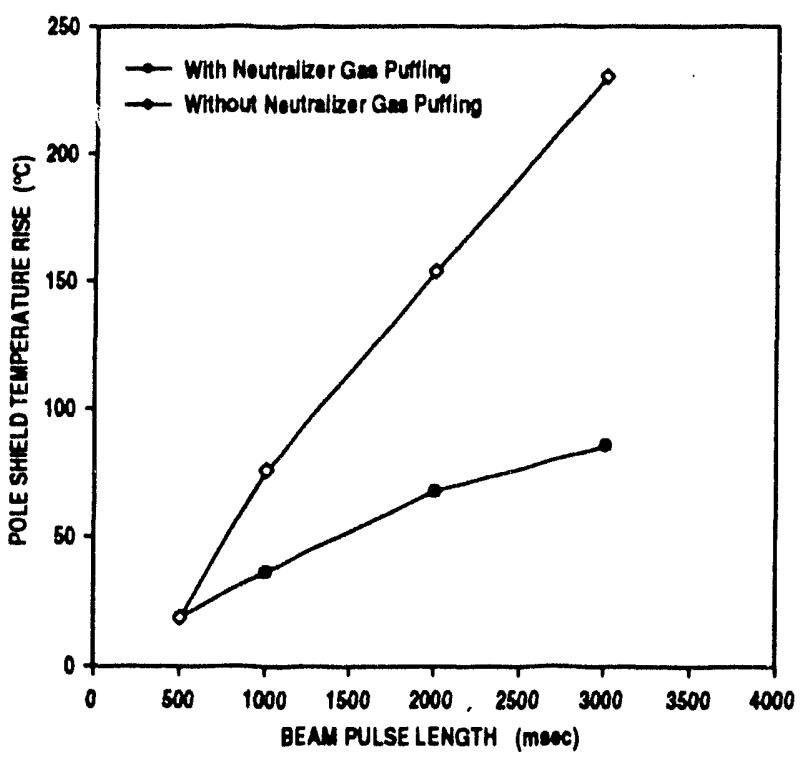

F10. 6. Temperature rises on the magnet pole shields sie significantly larger in the absence of neutralizer gas puffing.

\section{CONCLUSIONS}

The time-dependent data presented in this study represents a significant increase in accuracy and thus confidence over previous extrapolations using the two time point thermocouple readings. By limiting beam power to the operating space mapped, extended pulse length operation of $10 \mathrm{sec}, 60 \mathrm{kV}, 1.5 \mathrm{MW}$ per beam can be achieved using the existing beamline hardware. The use of real-time interlocks both for drift duct safety and to assure proper neutralization efficiency will allow this to be done with added confidence. By improving the power handling of the magnet exit collimator (Fig. 5) by means of hardware modifications inside the beamline (the magnet exit collimator is a component separate from the magnet assembly and can be serviced during routine beamline entries), this operating space may be expanded modestly at relatively minor cost.

\section{ACKNOWLEDGMENTS}

The support and efforts of neutral beam operator Matt Madruga and power supply technicians Don Clow, Jim Schroeder, and Pete Showalter (particularly in the operation of the Nicolet waveform analyzer) are gratefully acknowledged.

\section{REFERENCES}

[1] R. Hong, A.P. Colleraine, D.H. Kellman, J. Kim, J.L. Luxon, A. Nerem, et a., "Enhancement of DIII-D neutral beam aystem for higher performance," in Proc. Symp. an Fusion Technology, Rome, 1982.

[2] A.P. Colleraine, R.W. Callis, R.-M. Hong, D. Kellman, J. Kim, A.R. Langhorn, et a., "Increased power delivery from the DIII-D neutral beam injection system," in Proc. 13th IEEE Symp. an Flusion Engineering, 1989.

[3] J.T. Scoville, R.J. La Haye, A.G. Kellnuan, T.H. Ouborne, R.D. Stambaugh, E.J. Strait, and T.S. Toylor, "Locked modes in DIII-D and a method for prevention of the low density mode," Nucl. Fusion, vol. 31, p. 875, 1991.

[4] J. Wight, R.M. Hong, and J. Phillips, "Recent DIII-D neutral beam calibration results," in Proc. 14th IEEE/NPSS Symp. on Fusion Engineering, San Diego, vol. I, p. 136, 1991. 

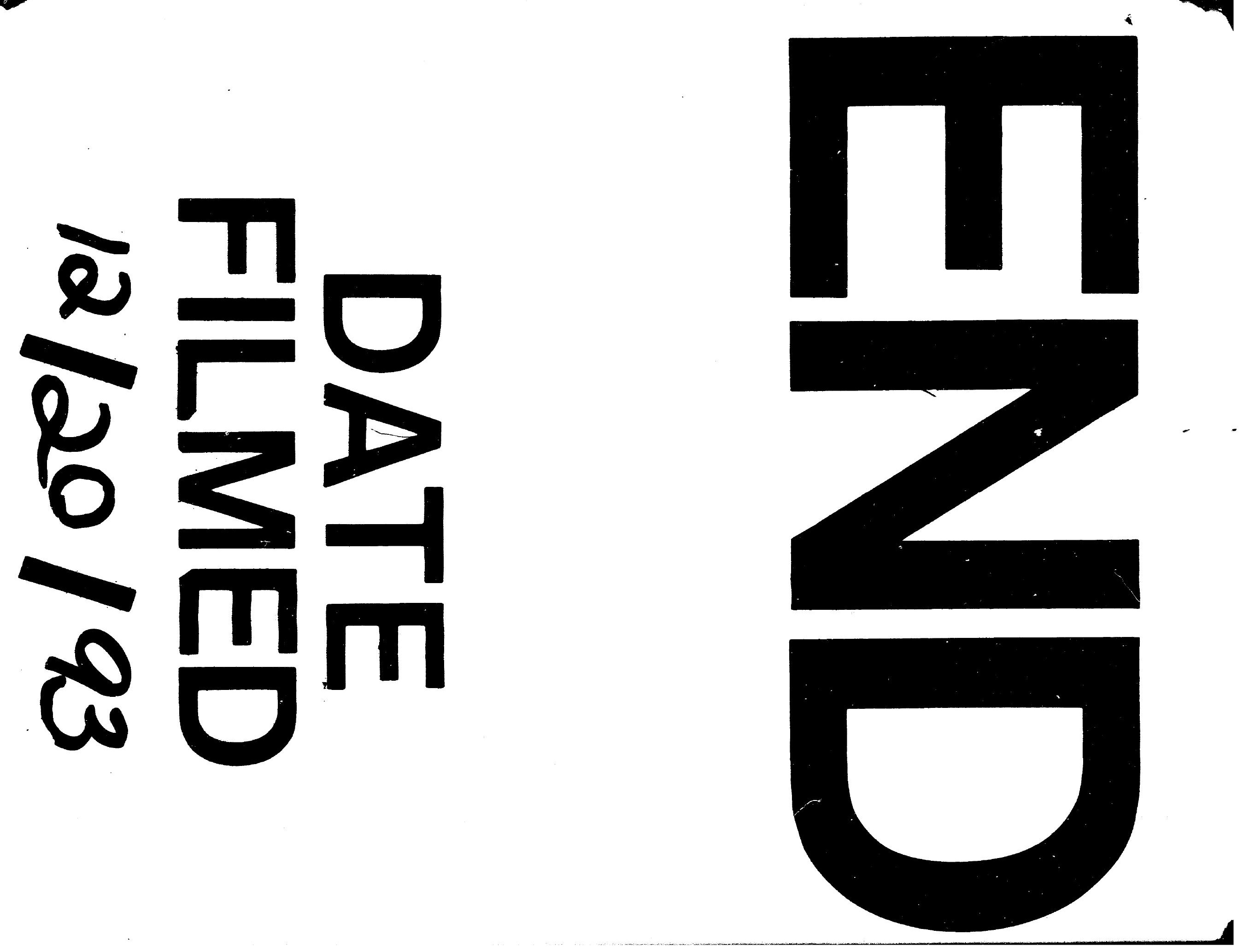


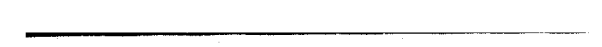

